\title{
LA FORMACIÓN DEL ESTADO Y LOS MAPUCHE(S) O LOS MAPUCHE(S) Y LA FORMACIÓN DEL ESTADO NACIONAL EN CHILE ${ }^{1}$
}

\author{
José Bengoa Cabello
}

1 Dada la controversia acerca de escribir mapuche en plural, con "s", o sin "s", el autor se inclina por colocar la "s" entre paréntesis, como una forma de reconocer la postura de quienes abogan por quitar la "s" en todos los casos, plural por cierto, y prevenir al lector de que no se trata de un error gramatical. 


\section{JOSÉ BENGOA CABELLO}

Es Licenciado en Filosofía y se ha especializado en temas de historia y cultura. Fue miembro del Centro de Estudios Socioeconómicos de la Facultad de Economía de la Universidad de Chile y fundó la Escuela de Antropología de la Academia de Humanismo Cristiano, universidad de la que fue rector en dos oportunidades. Actualmente se desempeña como profesor en dicha Escuela. Es autor, entre muchas otras obras, de Historia del pueblo mapuche (1985), Historia rural de Chile central (2015) y Reforma Agraria y revuelta campesina, editado en 2016 por LOM. 


\section{LA FORMACIÓN DEL ESTADO Y LOS MAPUCHE(S) O LOS MAPUCHE(S) Y LA FORMACIÓN DEL ESTADO NACIONAL EN CHILE}

En este artículo trataremos la relación existente entre los mapuche(s), anteriormente denominados araucanos, y la formación del Estado y la sociedad en Chile ${ }^{2}$. Señalaremos que muchas de las características que ha tenido y sigue teniendo el Estado chileno se originan en la existencia de una frontera de guerra en el sur. Agregaremos que la existencia de un conflicto nunca resuelto también ha sido y sigue siendo un factor de la mayor importancia en la constitución del Estado y numerosas características de la sociedad. En este aspecto no es menor la consideración de la existencia de un "pueblo originario" anterior al chileno, para algunos "el ancestro", que cumple, además de los elementos evidentes del conflicto, un papel simbólico y muchas veces psicoanalítico en las consideraciones propias de la autopercepción acerca de la nación chilena. Asuntos relacionados con la pertenencia o no a las culturas europeas occidentales, a las formas de vida hispanoeuropeas, a las imágenes de los cuerpos y los elementos fundantes del racismo, surgen de la oposición entre "lo indio" y lo "no indio", entre lo que en el siglo XIX se señalaba con todo desparpajo como la oposición entre "civilización y barbarie". Si bien hoy por hoy muchas de estas ideas avergüenzan a quienes las consideran correctas y las callan en público, suelen ser mucho más comunes de lo que se cree y sobre todo las consecuencias en los actos ordinarios, comunes e institucionales, son de toda evidencia. Si bien no suelen ser expresadas públicamente, son el "secreto de familia" de la sociedad chilena.

Pero así como haber tenido en el sur de Chile ${ }^{3}$ una frontera de guerra, y en cierto modo seguir teniéndola en pleno siglo XXI, ha tenido consecuencias enormes en la conformación de las instituciones y en la cultura del resto del país, así también los propios indígenas se han moldeado, se han constituido en la oposición a la "sociedad global", como gustaban de decir los indigenistas del siglo XX. En los hechos, el tránsito lingüístico desde el apelativo "araucano" al de "mapuche" es de data muy reciente. Mapuche es una palabra que aparece desde un inicio en la lengua

2. La Revista Anales de la Universidad de Chile nos ha solicitado un artículo sobre este asunto para un número especial a publicar el año 2018.

3. La oposición de lo indio en el norte de Chile, siendo muy importante, no la vamos a tratar en este artículo por razones principalmente de extensión. 
de la tierra (la lengua de Chile o chiledugu, al decir de Havestadt ${ }^{4}$ y que consignan los cronistas españoles. Sin embargo, no era un patronímico genérico que denominara a un conjunto enorme de grupos, agrupaciones y personas ${ }^{5}$. Pareciera ser ese el motivo por el que los españoles, al no encontrar un nombre genérico, optaron por darles un nombre que los abarcara a todos, esto es, araucanos ${ }^{6}$. Huilliches es el apelativo más común que aparece en las crónicas y desde el inicio se mencionaba a los pehuenches, que habitaban entre la cordillera y los faldeos orientales en lo que hoy es el Neuquén, de la Argentina. Picones, pikunches y un sin número de apelaciones en el norte complejizan mucho más el panorama; los cuncos, en el sur, serían los que hoy en día se auto reconocen como huilliches. En muchos casos los españoles no saben si el apelativo corresponde al río o al cacique de la agrupación que allí habita, como en el caso del Maule. En muchos casos el apelativo mapuche significaba "ser de ahí", o si se quiere, en primera persona, "yo soy de aquí" (inche mapu che) y no necesariamente un patronímico genérico de un conglomerado.

En el siglo XX se producirá un fenómeno muy interesante en la medida en que las propias agrupaciones indígenas, transversales a las diversas denominaciones regionales, locales o comunitarias, se autodefinirán como araucanas. Tomarán la apelación genérica del conquistador y la harán suya. Es así que una de las primeras, sino la primera, se autodenominará Sociedad Caupolicán Defensora de la Araucanía, asumiendo dos denominaciones del poema de Ercilla: el héroe Caupolicán y el territorio como Araucanía. Luego vendrán muchas más: la Federación Araucana de Aburto Panguilef, la Corporación Araucana de Venancio Coñoepan y numerosas otras en las que el apelativo común será la denominación "araucano" . Será a fines de los ' 60 y sobre todo en los '70 en que se cambiará paulatinamente la denominación por la de mapuche. En los últimos 25 años esta ha ido ganando espacio y legitimidad, de tal suerte que se van disolviendo las auto identidades que se denominan de otro modo, como por ejemplo las de huilliches.

4. Bernardo Havestadt, Chilidúgú, sive Res chilenses vel descriptio status tum naturalis, tum civilis, cum moralis Regni populique Chilensis inserta suis locis perfecta ad Chilensem Limguam Manuductioni deo O.M. multis ac miris modis Jwvante. Lipsiae: Typis B. G. Teubneri, 1777. 3 t. en 2 v. Ver facsimilar en www. memoriachilena.cl

5. La discusión en esta materia está abierta. El padre Diego Rosales señala que el valle del Mapocho viene de la deformación del valle de los Mapuche o donde se habría hablado la lengua de la tierra, esto es, de los mapuche. No sabemos si se denominaba de esta manera a las personas o la lengua que hablaban.

6. La palabra provendría de un río en la zona hoy llamada de Arauco, que se habría denominado Ragco. "Co" es "agua" y "Rag" sería "barrosa”. De ahí se habría deformado como "Arauco". Alonso de Ercilla la lleva al poemario titulando su obra como "La Araucana".

7. Ver José Bengoa. Mapuche, colonos y el Estado nacional. Catalonia. 2015. 
La contra tesis que en este artículo tratamos de señalar es que la relación con el Estado chileno, y recientemente con el argentino, ha producido también un proceso de unificación en torno al concepto de mapuche, y de allí a la construcción de un concepto de pueblo nación y crecientemente a uno de territorio (wallmapu) y de Estado nación ${ }^{8}$.

Así como la presencia de una frontera de guerra ha contribuido en la formación del Estado chileno, también la delimitación étnica nacional y el conflicto han colaborado en la construcción de una entidad con cada vez mayor personalidad, que es la del pueblo mapuche.

\section{LA GUERRA DE ARAUCO Y LA FORMACIÓN DEL ESTADO}

La tesis acerca de la importancia de la Guerra de Arauco en la formación del Estado nacional chileno ha sido desarrollada con singular brillantez por los mejores historiadores chilenos del siglo XX. El Profesor Mario Góngora la analizó en diversos escritos y sobre todo en sus conferencias, señalando que como consecuencia de la incesante guerra del sur fronterizo se fue forjando el "alma nacional". Características que permanecen hasta hoy en el Estado chileno provendrían de ese momento fundacional: por ejemplo, el "centralismo" político; el autoritarismo y manejo "cuasi militar" de los asuntos públicos; y, sobre todo en su último libro, el carácter presidencial del poder en Chile, no solamente a nivel de la República sino de cada una de sus partes y organizaciones subalternas (Vgr. alcaldes). Góngora habría dicho de manera coloquial, hoy en día, que esos españoles con un ADN monárquico se enfrentaron a los araucanos como lo habrían hecho con los moros. La República que se independiza de la España en crisis no cambia nada de ese profundo "ser nacional", sino que lo restaura portalianamente. En definitiva, su tesis dirá que en Chile fue el Estado el que formó a la sociedad y no al revés, como se podría pensar usando teorías de orígenes extranjeros?.

8. Wallmapu es un concepto y término de reciente uso, aunque la traducción como "País Mapuche" es muy antigua en cronistas y viajeros. El concepto proviene de los debates actuales en ciencias sociales sobre el significado de los "territorios", que es mucho más que la tierra agrícola y productiva; se trata de un concepto que abarcaría el medio ambiente, la espiritualidad del territorio, su identidad; en fin, una compleja y sin duda muy rica mirada del espacio en el cual se ha vivido, se vive y se vivirá.

9. "La nacionalidad chilena ha sido formada por un Estado que ha antecedido a ella, a semejanza, en esto, de la Argentina; y a diferencia de México y del Perú, donde grandes culturas autóctonas prefiguraron los virreinatos y las repúblicas. Durante la Colonia se desarrolla un sentimiento regional criollo, un amor a 'la patria' en su sentido de tierra natal, de que nos dan amplios 
El profesor Álvaro Jara sostiene, por su parte, una tesis similar pero de tinte menos hispanófilo que Góngora, y por tanto más matizada en algunos aspectos. Pero en el clásico libro Chile, guerra y sociedad ${ }^{10}$ no deja de maravillarse de las consecuencias que tendría la Guerra de Arauco en la formación de la sociedad chilena. Su gigantesca obra sobre el Trabajo en Chile $e^{11}$ es la vertiente crítica de esta teoría, ya que el autoritarismo militar producto de y producido por la Guerra de Arauco se va a transformar en esclavitud, trabajo forzado, trabajo duro y autoritarismo laboral hasta el día de hoy.

No cabe mucha duda de que esta es una de las tesis de mayor interés y capacidad explicativa que ha desarrollado la historiografía chilena para unir el hecho de la resistencia araucana (hoy dicha mapuche) y la formación del Estado y sociedad chilena. Hasta acá no tendríamos mayor justificación de escribir estas líneas sobre este tema solicitado por la Revista Anales de la Universidad de Chile.

Sin embargo, a pesar de estar de acuerdo con la tesis, hay algunas preguntas secundarias pero de la más alta importancia que nos podríamos formular al comenzar el siglo XXI.

La primera tiene que ver con el sentido de la historia. Ese hecho singular ocurrido en nuestra historia colonial y republicana, ¿es un factor positivo o negativo en la formación del Estado y la sociedad chilena? Para Mario Góngora, en los años de madurez, no en su juventud, se fue transformando cada vez más en un elemento positivo. Para Álvaro Jara, en sus años de madurez y sobre todo de vejez lúcida, se fue volviendo parte de la carga pesada del mundo colonial sobre la frustrada y parcial modernidad de esta sociedad. Para nosotros, mirando la historia como siempre se hace, desde el presente hacia atrás, la guerra ha sido y es la explicación y causa de la fuerza enorme que tiene el conservadurismo en Chile, el autoritarismo del Estado, las relaciones de subordinación laboral, social y de todo orden en la vida cotidiana, y sobre todo del racismo metido hasta los tuétanos en la cultura chilena ordinaria. De eso hablaremos en un primer capítulo de este ensayo.

testimonios los cronistas". Mario Góngora. Ensayo histórico sobre la noción de Estado en Chile en los siglos XIX y XX, Ediciones La Ciudad. Santiago. 1981. Es necesario recordar que el primer capítulo de este importante libro se denomina: "Chile, tierra de guerra".

10. Álvaro Jara. Chile, guerra y sociedad. Editorial Universitaria. Santiago. 1971. La tesis en francés era del año 1961. En el prólogo a la segunda edición es explícito al señalar: "La tesis central de la vinculación y el desarrollo interconectado de las formas bélicas y las formas sociales siguen siendo la columna vertebral, la clave interpretativa para ese periodo de nuestra Historia".

11. Álvaro Jara y Sonia Pinto. Fuentes para la historia del trabajo en el reino de Chile. 1546-1810; segunda edición. Dos volúmenes. Editorial Andrés Bello. 1982. 
Y lo segundo tiene que ver con el título reversible de este ensayo. Porque efectivamente la existencia de un pueblo irredento en el sur de Chile y de un Estado no indígena en el valle central marcó la conformación de la sociedad chilena (guerra y sociedad), pero al mismo tiempo (y también) construyó al propio "pueblo mapuche"; lo construyó como "pueblo" y hoy por hoy como "pueblo nación", al decir de sus líderes e intelectuales. Como toda "relación espejo", las figuras se delinean frente a "el otro" 12 .

La tercera observación, o derivada, a la tesis tradicional comentada se refiere, mutatis mutandis, a cuán deudora del psicoanálisis es la tesis que acá estamos explicitando. Porque la sociedad chilena, quizá exagerando las tintas meditadamente, ha formado su identidad (nacional, podríamos decir) en la oposición, como el hijo (Edipo) la debe formar frente a su padre (e incluso intentar matarlo) ${ }^{13}$. Y no cabe mucha duda de que el intento de matar al ancestro ha sido la constante de nuestra fortaleza identitaria desde que llegó el conquistador hasta la actualidad, en que un candidato (2018) bien votado (sobre todo en La Araucanía) ofrecía correr bala y cambiar los cartuchos con balines de goma por hierro duro y puro. Y se podría agregar: "nadie dijo nada". El juego simbólico, a veces ambiguo y muchas veces confuso (o perverso), entre el "heroico araucano" y el "indio salvaje" se ubica en el centro de la cultura nacional y popular, en sus emblemas ("la sangre araucana") ${ }^{14}$.

12. El libro más interesante de Mario Góngora, a nuestro modesto modo de ver, es El origen de los inquilinos del valle central de Chile, en el que basado en mucho material de primera mano va mostrando el carácter predominantemente hispano del origen del pueblo chileno del valle central luego de la extinción casi completa de los indígenas al norte del río Biobío. Muchos han (y hemos con mucho cuidado) criticado estas tesis en la medida en que le otorgan menor importancia al mestizaje. Lo importante es que Góngora muestra que las diferencias entre "el pueblo" del valle central y su contraparte del sur de Chile tienen un carácter étnico profundo, un origen en que el mestizaje de la zona central es hispano-dominante y en la zona sur indígenadominante, con todas las consecuencias que son fáciles de imaginar. Como se ha dicho muchas veces, la desaparición de los indígenas (y población negra) del valle central se produjo primero en el imaginario social y luego en la realidad de los hechos.

13. Sófocles cuenta la historia de Edipo, que mata a su padre, Layo, sin saberlo y luego se casa con Yocasta, su madre, reina de Tebas. Al saberlo se saca los ojos y vaga por el mundo ayudado de su hija Antígona. Freud ve en este acto de matar al padre y casarse con la madre un juego de oposiciones formativas de la personalidad humana.

14. La alusión permanente al color "rojo" que lleva la bandera nacional y se dice hasta el cansancio que sería en honor a la "sangre araucana"; la "roja y la rojita" para simpatizar con la camiseta de la selección de futbol; en fin. Tras el asiento del escritorio del Comandante en Jefe del Ejército está colgado el cuadro original de Lautaro pintado por Pedro Subercaseaux y en los textos que estudian los jóvenes oficiales del Ejército aprenden que el primer ejército que hubo en Chile fue el de Lautaro, viniendo después el de Bernardo O’Higgins y finalmente el prusiano moderno. Se trata de la historia militar del general Agustín Toro Dávila, Sintesis histórico militar de Chile. Dos 
Pero por otro lado podemos echar mano de un proto Hege ${ }^{15}$ en que el señor, al perdonarle la vida al siervo, al convertirlo en su fuerza de trabajo, le da un espacio de autonomía de tal suerte que también puede forjar una identidad contrapuesta (La lucha de las autoconciencias contrapuestas en la traducción de Wenceslao Roces). Y es lo que ha ocurrido históricamente. Los siervos originarios ${ }^{16}$, esclavos cobrizos atrapados en la guerra ${ }^{17}$, se fueron convirtiendo en un colectivo autónomo, en un largo proceso de etnogénesis ${ }^{18}$, en un pueblo. Este proceso fue lento y aún no ha concluido.

Podríamos resumir esta contra tesis señalando que la sociedad mapuche (y sus crecientes demandas proto estatales) se ha formado (construido) en la medida en que existe en la sociedad y el Estado chileno la conciencia permanente o espíritu de conquista ${ }^{19}$. Más aún, mientras mayor es el ímpetu conquistador del Estado, mayor es la auto conciencia de singularidad, derechos vulnerados y reivindicaciones sucesivas y en aumento.

Concluyendo con la ayuda de Hegel, se podría decir que el señor se ve vulnerado por la creciente autonomía del siervo y manifiesta de manera cada vez más explícita

tomos. Editorial Universitaria. Santiago. 1977. Hemos escrito anteriormente que en un acto de extrañas connotaciones psicosociales, a pocos días de ocurrido el 11 de septiembre de 1973 los niños de la Escuela Militar fueron llevados a la localidad de Nehuentúe, al mando del coronel de apellido Ewing, a maniobras en pleno territorio mapuche, produciéndose una represión extremadamente fuerte. Es de esas casualidades que no son casuales.

15. Me refiero al capítulo IV de la Fenomenología del espíritu, "La verdad y la certeza de sí mismo" y en particular el párrafo 2, "la lucha de las autoconciencias contrapuestas", y el tercero, el ampliamente conocido señor y siervo. Fondo de Cultura Económica. Traducción de Wenceslao Roces. 1966.

16. Toda la demanda hispánica consistía en transformar a los indígenas en "siervos". "No nos quieren servir", se quejaban amargamente. El sistema de encomiendas, para quien no lo recuerde, se denominaba el "servicio personal". Y los araucanos (hoy mapuche(s)), se arrancaban y no aceptaban el servicio, esto es, la servidumbre.

17. Me refiero a la "esclavitud cobriza" que de ese modo se distinguía de la "esclavitud negra".

18. Es lo central del trabajo de Guillaume Boccara: comprender el modo como una sociedad formada por múltiples agrupaciones, que él denomina "reche", se va conformando y continúa formándose como "pueblo" a través de procesos cada vez más profundos y complejos de auto conciencia y auto reconocimiento, tales como el de pueblo nación o simplemente nación mapuche. Ver: Guillaume Boccara. Los vencedores. Historia del pueblo mapuche en la época colonial. San Pedro de Atacama. 2007.

19. Ver columna de José Bengoa "Jamás vencidos", en la Revista The Clinic (Jueves 5 de octubre de 2017), en que se critica la "Operación Huracán” que levantó el Gobierno chileno con gran algarabía en 2017, tomando presos a muchos dirigentes, acusándolos de faltas y “desvergüenzas” exactamente iguales (y con las mismas palabras, sin saberlo, de por cierto) que en el tiempo colonial. Una vez más ese huracán concluyó en brisas primaverales. 
su impotencia. "Vemos que su acción real deviene, por tanto, una acción de nada, y su goce deviene el sentimiento de su desventura", dice el filósofo. Es finalmente lo propio de los procesos de de(s)colonización ${ }^{20}$, en que el colonizador se ve impotente ante la acción del colonizado y su poderío ("goce") comienza a transformarse en sufrimiento, tragedia, desesperación, en fin, lo que en el lenguaje hegeliano es "el sentimiento de su desventura"21. La acusación de "terrorismo" es en este juego dialéctico la propia conciencia del terror, el miedo a perder la dominación, el dominio sobre el otro ${ }^{22}$.

20. "Una de las contradicciones y paradojas centrales que caracterizan el colonialismo republicano en Wallmapu ha sido, entonces, la falaz apelación a la igualdad, homogeneidad, a los discursos liberales y de derechos universales, para promover la incorporación mapuche como ciudadano de segunda categoría. En los hechos, incluso se nos ha negado nuestra "condición humana", animalizándonos bajo representaciones coloniales (antes "bárbaro"/salvaje", ahora "terrorista"), expropiando nuestra capacidad de mando y autogobierno de nuestras propias vidas en los diferentes ámbitos de la realidad social (económico, político, educativo, lingüístico, etc.) y explotándonos como fuerza de trabajo racializada para beneficio de las clases medias y altas en Chile. La inserción mapuche como mano de obra agrícola, obrera y doméstica en espacios rurales y urbanos es el correlato de estos procesos". Héctor Nahuelpan y Jaime Antimil - Descolonización y desracialización en Chile. Una breve reflexión para la Federación Mapuche de Estudiantes / Comunidad de Historia Mapuche - Centro de Estudios e Investigaciones Mapuche. Fuente: comunidadhistoriamapuche.org. Hay una compleja discusión en torno a escribir descolonización o decolonización, por lo cual al no pronunciarnos lo ponemos entre paréntesis.

21. El señorío local (o regional) de los colonos extranjeros llegados a comienzos del siglo XX a La Araucanía ya ha comprendido la incapacidad de resolver el asunto contencioso y muchos de ellos abandonan el campo, la agricultura, se quejan de no tener mano de obra ("no nos quieren servir", como decían los antiguos españoles) y no pocos renuevan sus pasaportes suizos por si en algún momento se produce una estampida en la que hay que regresar a la casa de los bisabuelos. Ver: José Bengoa. Mapuches, colonos y el Estado nacional, ya citado.

22. "La verdad de la conciencia independiente es la conciencia servil... Pero así como el señorío revelaba que su esencia es lo inverso de aquello que quiere ser, así también la servidumbre devendrá también, sin duda, al realizarse plenamente lo contrario de lo que de un modo inmediato es: retomará a sí como conciencia repelida sobre sí misma y se convertirá en verdadera independencia" (página 119, edición citada). En el caso Luschinger, en que murieron quemados una pareja en su casa incendiada en el campo cercano a Temuco, se señala que una hermana de la machi Francisca Linconao, acusada de participar en ese evento, trabajaba de empleada doméstica en la casa de esa familia y que la misma machi era muy amiga de la casa, lo que se señala como algo incomprensible; Hegel, hace ya mucho tiempo, en su lenguaje complicado, permite comprenderlo como algo bastante común a los seres humanos. 


\section{DEL ESTADO OLIGARQUICO, LA GUERRA DE ARAUCO Y EL MODELO CONSERVADOR SUBYACENTE A LA SOCIEDAD DEL VALLE CENTRAL DE CHILE}

Lo primero que es preciso recordar nuevamente, por su importancia, es la desocupación violenta del valle central de Chile. La historia es conocida ${ }^{23}$. En los dos tomos citados de Álvaro Jara sobre el trabajo y esclavitud en Chile están los documentos. En su informe, Santillán ahorra comentarios. Lo concreto es que 50 años después de llegados los conquistadores, la población indígena de la zona central de Chile es muy pequeña o está casi extinguida. Ginés de Lillo es enviado a hacer las "Mensuras"24 que llevan su nombre y describe con minuciosidad los pocos habitantes que quedaban en las "rancherías". El propio Valdivia, antes de partir al sur en su afán de conquista que le llevará a la muerte, vuelve a repartir las magras encomiendas, lo que llena de ira a sus compañeros. Los señores no lograron que los indígenas se transformaran en siervos y los extinguieron mortalmente de desesperación. Podríamos agregar, parafraseando y jugando con conceptos aparentemente añejos, que "el sentimiento de su desventura" se fue quedando pegado al alma nacional.

Grandes territorios en manos de un puñado de "estancieros", como lo estableció Góngora $^{25}$. Escasa mano de obra y en algunos lugares, casi nula. Enormes espacios vacíos que se van llenando de a poco con españoles pobres y sobre todo con los exiliados del sur cuando en el cambio de siglo (1600) son expulsados masivamente de Valdivia y las ciudades arrasadas por los araucanos. Alonso de Rivera le pide al rey que le entregue poderes para establecer a los refugiados en la tierra, darles propiedad privada y eterna de modo que no se vayan del país, cosa que muchos querían hacer, muertos de miedo y habiendo perdido casi todo lo que habían construido ${ }^{26}$. En la

23. Ver nuestra Historia rural del valle central de Chile. Dos tomos. Editorial LOM. Santiago. 2016. En particular el capítulo primero sobre el valle del Mapocho.

24. Ginés de Lillo. Mensuras de Ginés de Lillo. Colección de Historiadores de Chile y Documentos Relativos a la Historia Nacional. Volumen XLIX. Introducción de Aniceto Almeyda. Santiago de Chile, Imprenta Universitaria. 1942.

25. Mario Góngora, Encomenderos y estancieros. Estudio acerca de la constitución social aristocrática de Chile después de la conquista. 1580-1660. Universidad de Chile. Sede Valparaíso. 1970. Góngora señala que ese periodo es clave en la historia de Chile, ya que se habían acabado los lavaderos de oro, "la ruina de los pueblos de indios y el incremento de las estancias. En suma, entre 1580 y 1610 apareció una nueva fisonomía totalmente imprevista e imprevisible en el primer momento".

26. Publicamos la fotografía original de este decreto real que instaura por primera vez la propiedad privada agrícola en Chile, que obtuvimos del Archivo de Indias en Sevilla. Ver: Historia social de la agricultura chilena. Primer tomo. El poder y la subordinación. Ediciones Sur. Santiago. 1989. 
parte norte de la frontera, Chillán, Portezuelo, Rafael, Pinto, etc... les dará tierras a los pobres, a los antiguos soldados de la frontera, de modo de construir un escudo contra los rebeldes, la denominada barbarie. Frontera humana, de mayoría española, que al igual que los romanos en el Rhin, protejan al valle central. A los oficiales, a los que tienen más contactos y señoría, les entregan tierras de mayor tamaño y así se puebla Linares, San Javier, Talca y se va "asentando" la zona central.

Góngora nos cuenta de un capitán llamado Martín de Espinoza y Santander que era "Hijo de un vecino de Imperialy de Valdivia; este Capitán fue dueño de tierras de la Hacienda de Quillota (la más rica en esos tiempos y que al comienzo perteneció al mismo Pedro de Valdivia como encomendero), que fue de sus padres, con casa, viña, bodega, arboleda, ganados, 17 esclavos negros de todas edades, y 1 esclavo auca; y de la estancia de Chocalán, compradas a sus suegros en 1632, con ganados y un obraje de garcias..." (Testamento de 1660) ${ }^{27}$.

Este es un caso que hemos analizado muchas veces, ya que el mito familiar (por cierto no comprobado) señala que las tierras le fueron entregadas en Quillota a Espinoza y Santander padre cuando era joven por haber galopado desde la batalla de Tucapel, en el sur de Chile, hasta Santiago y haber dado aviso de la muerte del gobernador Pedro de Valdivia. Esta hacienda, que se unía con la de Chocalán, famosa por sus palmas de las que se obtiene la miel (hoy Parque Nacional de la Campana), perteneció durante 400 años a la misma familia (1660, fecha del testamento, a 1967, fecha de su expropiación por la Reforma Agraria), lo cual expresa de modo evidente la "estabilidad del latifundio" en el Chile central. Y además, el origen de esta estructura en la Guerra de Arauco. ${ }^{28}$

27. Mario Góngora. Encomenderos y estancieros, edición citada, página 217.

28. Andrés de Santander era criado del marqués de Cañete, Hurtado de Mendoza, y pasa a América en 1555. Martín Espinoza y Santander, por su parte, vino al Perú con el adelantado Gerónimo de Alderete en 1555; pasó a Chile como criado del gobernador García de Mendoza con título de capitán; asiste a las batallas de Lagunillas, Biobío y Millarapue; estuvo en la repoblación de Concepción, Arauco, Tucapel, Osorno, Purén y Mendoza; presente en el descubrimiento de Chiloé; vecino encomendero de Cuyo 1561-1565 y de Guantata; residente en Valdivia 1583; la historia sigue y después de la destrucción de Valdivia el padre Diego Rosales dice que "este don Martín, que había sido vecino muy rico de Valdivia por 1646, recorrió la Mariquina, tratando de rescatar parientes cautivos... fue por mar a Valdivia desde Santiago con deseos de sacar de cautiverio a una hermana suya que en el alzamiento general y la pérdida de la ciudad de Valdivia, cincuenta años antes (sic) la habían cautivado los indios, y viniendo acaso con el Gobernador de Valdivia, inopinadamente se encontró con ella y la sacó de cautiverio, llorando los dos de gozo y no pudiendo hablarse en gran rato por la ternura". El Martín al que se refiere Góngora en la cita de más arriba sería Martín de Espinosa Santander y Olivares, quien nació en el valle de Quillota el 2 febrero 1608; sirvió en la Guerra de Arauco en diversos puntos desde 1625; capitán; maestre de campo; dueño de las estancias de Chocalán y Quillota; testó en Santiago en 1660. Ver: Julio Retamal Favereau, Carlos Celis Atria y Juan Guillermo Muñoz Correa, Familias fundadoras de Chile, 1540-1600, Editorial Universitaria, Santiago, 1992. 
Pero lo notable de este documento (y otros semejantes) es que en Quillota ya no quedaban indígenas locales como mano de obra y el campo se manejaba con esclavos negros y un esclavo mapuche prisionero de guerra al que se denominaba como "auca". En una carta que envía el mismo propietario al rey para desarrollar las fábricas de garcias (cordeles, cuerdas necesarias para el uso de los barcos), señala que lo pueden hacer todos aquellos que tienen un número de 16 trabajadores y que era un puñado de encomenderos/estancieros. Recordemos solamente que en Quillota había, al llegar Valdivia, un mitimae abundante en población de origen quechua, y en los primeros años se trasladaron grandes cantidades de indígenas del valle del Mapocho a trabajar en los lavaderos de oro de Marga Marga. Los indígenas de la zona dejaron su recuerdo en la toponimia quechua y mapuche y fueron extinguidos del modo más violento imaginable en pocos años ${ }^{29}$.

La hacienda ha sido la institución más antigua y permanente en la historia de Chile, sólo equiparable a la Iglesia (por cierto, la Católica), con la que son hermanas gemelas. Cada casona de campo o casa de haciendas tiene hasta hoy pegada una iglesia, en algunos casos de gran hermosura. Esta institución surge de la desocupación poblacional del valle central y del reparto de tierras entre los soldados y oficiales de la guerra. Es el botín.

En Chile se instaura el "botín de guerra" como derecho. Rousseau dirá que se trata del "primer ocupante", por cierto después de muertos los originarios y sobre todo del "derecho del más fuerte", las dos fuentes del derecho según el sabio ginebrino ${ }^{30}$.

Góngora ha descrito como nadie la formación de las haciendas en el valle central, en las tierras cercanas a Melipilla, María Pinto y Curacaví, caracterizada por la existencia de un estero que baja de los cerros de Colliguay, cruza el valle de Curacaví y se va metiendo de norte a sur hasta caer, cuando tiene agua, en el

29. Quillota es una voz de origen al parecer quechua o aymara deformada, pero no provendría del mapudungun; Tabón fue el nombre de un cacique y se lo recuerda en la "cuesta del Tabón”. Era del valle del Mapocho, probablemente, él y su gente.

30. No quisiéramos extremar los argumentos, pero el "botín" es en la historia chilena un derecho adquirido. Señalemos solamente el comportamiento de las tropas chilenas en su ingreso a Lima. Hicimos una campaña por la devolución de los libros robados a la Biblioteca Nacional del Perú (y también a la del escritor Ricardo Palma) y fuimos violentamente criticados en el diario El Mercurio, entre otros por un Premio Nacional de Historia. Nadie podría desconocer que el golpe de Estado de 1973 consideró como legítimo un botín de guerra cuantioso que se repartió entre quienes habían sostenido el putsch y la dictadura. Empresas del Estado, como la Compañía de Aceros del Pacífico, Empresa Nacional de Energía y otras que hoy se precian de ser obras de la libre competencia, fueron vilmente robadas como botín de guerra por civiles y militares coludidos. Y nadie dijo nada, salvo la Premio Nacional de Periodismo María Olivia Mönckeberg (El saqueo de los grupos económicos al Estado de Chile, Ediciones B, 2001). 
Maipo. Góngora estudia junto al geógrafo Jean Borde la forma como se construyó la propiedad rural ${ }^{31}$. Los valles al norte de Santiago, llamados transversales, quizás fueron los primeros en que la población se "asentó". Estaban lejos del frente de guerra. El Valle del Maipo, del Mapocho y la zona central se fueron repoblando con gente que venía llegando de diferentes procedencias e incluso de España; mestizos de diferentes combinaciones, que se llamaron zambos, mulatos, morenos, en fin, lo que fue formando el pueblo de este país. Quedan como fragmentos de compleja interpretación los bailes chinos, que en Quillota tienen uno de sus centros, en que se combinan tradiciones probablemente quechua incásicas con costumbres musicales propias de los mapuche(s) y otros grupos étnicos que habitaban en esos lugares. ${ }^{32}$

José Donoso tiene una feliz imagen en Casa de Campo. Las rejas, dice, que protegen jardines, parques y casas de las haciendas en la zona central serían las antiguas lanzas que los conquistadores les arrebataron a los araucanos en la guerra de conquista. Esas lanzas, recuerda, ya las habían soltado de su base los mismos descendientes de los indios y llegó un momento, la Reforma Agraria, en que las tomaron y atacaron a los patrones, encastillados en sus fortalezas. No es demasiado distinta esta imagen literaria de otra mucho más histórica que trae Ramón Subercaseaux en sus Memorias de ochenta años. Recuerda allí la huelga de la carne a comienzos del siglo XX y que las tropas de la guarnición de Santiago realizaban ejercicios militares en San Bernardo. En ese momento queda sólo con un grupo de capataces y "enólogos franceses" en las casas de su hacienda del Llano, hoy por hoy conocido el lugar como El Llano Subercaseaux. Reparte rifles y escopetas y munición entre los suyos y se parapetan al ver que la turba se abalanzaba por calle San Diego hacia el sur. Su imaginación y buena pluma lo hacen recordar diciendo: "eran como los antiguos araucanos", agregando otro elemento subconsciente a los ya acá entregados, en que el "pueblo" alzado era visto como continuidad de los antiguos araucanos rebeldes.

Podríamos continuar con ejemplos diversos que muestran la estrecha relación entre las haciendas, el poder, la catolicidad y el frente de guerra fronterizo ${ }^{33}$. La

31. Jean Borde y Mario Góngora. Evolución de la propiedad rural en el Valle del Puangue. Editorial Universitaria. Santiago de Chile. 1956. Dos volúmenes.

32. Claudio Mercado. "Música y estados de conciencia en fiestas rituales de Chile Central". Revista Chilena de Antropología No 13. 1995- 1996. 163- 196. Facultad de Ciencias Sociales. Universidad de Chile, Santiago, Chile. Uno de los bailes más antiguos es el de Pachacamita, cerca de Quillota.

33. La geografía, otro derrotero, se explica ciertamente por el frente de guerra. Las ciudades, por ejemplo, de la zona central están ubicadas en forma precisa a una cantidad de leguas que eran las que podía hacer en una jornada el ejército que partía desde Santiago a las guerras de verano del sur araucano. Rancagua, San Fernando, Talca, Linares, Chillán, etc... se ubican a distancias semejantes (sólo diferencias menores por cursos de agua necesarios para el abastecimiento de hombres y bestias). 
hacienda se autodefinió como multiproductiva y tendiente al auto abastecimiento. Muy diferente a las haciendas de países vecinos y absolutamente diferente a las haciendas/plantaciones de tierras calientes. Acá se trataba de producir de todo un poco. Los inquilinos vivían encerrados en las haciendas y el mundo exterior era siempre fuente de peligros, de bandidaje, de afuerinos violentos ${ }^{34}$. Cuando estos últimos llegaban para las cosechas, las mujeres guardaban a las niñas jóvenes y ponían mucho cuidado en que no las vieran. En la zona del Maule, en que el bandidaje era muy común, las casas patronales eran verdaderas fortalezas y en su interior no solamente vivían los patrones y sus familias sino también capataces, mayordomos y personal de vigilancia cual guardias personales.

En definitiva, la propiedad, su estructura inamovible por siglos y siglos, surge de la guerra y ello no es menor. Sobre esa estructura de propiedad se formó por cierto la sociedad chilena, ricos y pobres, como habría dicho Recabarren, y sobre esa base estable, la estabilidad tan manoseada del Estado chileno, de su sistema jurídico y constitucional.

\section{DE LO QUE FUE PRIMERO, ¿EL ESTADO O LA SOCIEDAD? Y EL CARÁCTER CONSERVADOR DE LA CULTURA POPULAR}

En definitiva, a la extinción de la población indígena en el valle central le siguió la formación del pueblo chileno propiamente tal. Hay un corte producto de la guerra, como lo señalan con claridad Góngora y Jara en los textos clásicos citados. Se va a producir un quiebre de tal naturaleza que los nuevos hacendados comienzan a negarse a combatir en el sur de Chile, en la frontera de guerra. La vida en los campos, pobres pero tranquilos, de la zona central, con abundante comida y posibilidad de placeres sencillos, lleva a que pierda su cabeza el segundo gobernador de este reyno, "el afamado y muy gentil" Oñez de Loyola, emparentado con el santo fundador de los jesuitas y casado con una descendiente de los incas de Perú. La Corona debe organizar un ejército permanente y remunerado con el real situado.

Dos clases dominantes se van a constituir tempranamente, la de los hacendados del centro del país y la de los militares del sur fronterizo. La llegada de los vascongados producirá una mayor unidad entre comerciantes, los recién llegados de alpargatas y negocios de ultramarinos, como despreciativamente los trata Pablo Neruda, y los antiguos Valverdes de prosapia castellana, como los nombra Eduardo Barrios en

34. En la hacienda El Huique, en Colchagua, al borde del río Tinguiririca, en la noche se cerraban todos los portones y al puente techado se le ponía llave. Ver José Bengoa. El Huique. Memorias de la hacienda de los presidentes de Chile. Documental en You'Tube. 
Gran señor y rajadiablos. Ellos se autodefinirán y autodenominarán pretenciosamente como la "aristocracia castellano vasca" 35 . Si bien los del sur juegan un papel central en la Independencia de Chile, serán entre derrotados y $\operatorname{cooptados}^{36}$ por la clase terrateniente de la zona central. Van a quedar matices entre las diversas oligarquías regionales, pero la dominación socio-cultural del centro santiaguino será por 200 años incontrastable, hasta el día de hoy.

Surge el Estado sobre los cimientos fuertes de un sistema de propiedad hacendal articulado y estructurado. Bulnes es conocido por su capacidad de unir geográficamente la zona central del país; así al menos lo señala la placa que está en la base de su estatua en la plaza que lleva su nombre. Centralización militar del Estado. Plaza de Armas de Santiago, kilómetro cero del país que se construye como círculos concéntricos y expansivos. Lenguaje que se habla sin variaciones regionalistas ni entonaciones diversas como en Argentina y tantos países que surgen a partir de variados focos. Imaginario auto asignado de que somos una población blanca europea y que las diferencias no son por castas y etnias, sino por clases, ricos y pobres ${ }^{37}$. Sistema electoral parlamentario con sobre representación del mundo rural/agrario/hacendal ${ }^{38}$.

35. Ver María Rosaria Stabili. El sentimiento aristocrático. Editorial Andrés Bello. Santiago. 2001.

36. En Lircay, cerca de Talca, son derrotados y triunfa el centralismo en Chile hasta el día de hoy, y luego son cooptados de mil maneras; José Joaquín Prieto, quien va a iniciar la estabilidad del periodo republicano, había nacido en Concepción a fines del siglo XVIII. Bulnes, años más tarde, derrota al General José María de la Cruz, símbolo de la aristocracia militar penquista, primo del anterior (su segundo apellido era Prieto), y primo también de quien lo vence en la batalla de Loncomilla; había peleado en todas las batallas de la Independencia y se rebeló frente a Manuel Montt (1851) en uno de los últimos conatos de regionalismo. Sobre este asunto sigue siendo un clásico el estudio no traducido de Maurice Zeitlin. The civil wars in Chile. The bourgeois revolutions that never were. Princeton University Press. 1984. Ramón Freire, aunque nació en Santiago, hizo sus primeras armas en el Ejército de La Frontera en Concepción, llegando a ser Director Supremo. Su vida, llena de idas y vueltas, apasionante por cierto, culmina al perder la batalla de Lircay y luego sufrir el exilio en Tahiti (sic).

37. Tema no menor es la ausencia de fronteras étnicas al interior de la zona central, la que conduce a un intercambio sexual generalizado. En muchos países donde las fronteras étnicas internas son espesas, las mujeres del mundo popular no son siempre el objeto del deseo de los sectores ricos; en Chile el sistema feudal va a consagrar formas violentas incluso de seducción, violación e intercambio sexual, con profusión de hijos "huachos", y sistemas de "iniciación” de los jóvenes de la clase alta con las denominadas "chinas", empleadas y sobre todo hijas de los inquilinos y siervos de las haciendas. La literatura es la mejor fuente de estos asuntos, por ejemplo, José Donoso en Este domingo (Santiago. 1967) y el bien conocido relato llevado al cine denominado Julio comienza en julio (Gustavo Frías/Silvio Caiozzi).

38. Ver los listados de parlamentarios hacendados y la relación entre esta estructura y la institucionalidad republicana en: Arnold Bauer. La sociedad rural chilena: desde la conquista española a nuestros días. Editorial Andrés Bello. Santiago, 1994. 
La pregunta, por tanto, de ¿qué fue primero, el Estado o la sociedad? pareciera resuelta a esta altura de las investigaciones históricas: ni una ni la otra. Fueron ambas partes intrínsecamente relacionadas. No es por un lado posible explicar la temprana instalación del Estado en Chile central sin comprender la estabilidad a la que había llegado el régimen de haciendas y la cohesión de la oligarquía agraria de la zona central con predominancia sobre las regionales, tanto agro-minera del norte de Santiago, como la agro-militar fronteriza del sur. El Estado, al nacer, se organiza en torno a las instituciones que existían, la Iglesia y las haciendas. De hecho, serán las parroquias las únicas instituciones que agruparán a las poblaciones de pequeños pueblos, caseríos, etc., y las haciendas las que ordenarán el territorio, ejercerán justicia reprimiendo al bandidaje, en fin; curas y patronos eligiendo a autoridades, cohechando votos para el Parlamento, nombrando alcaldes si es que los había, sin contrapeso alguno hasta muy entrado el siglo XX y con fragmentos de poder hacendal que duran hasta el día de hoy como es bien fácil demostrarlo en elecciones de parlamentarios y en las votaciones del mundo rural, en que el voto cautivo sigue operando.

El modelo de dominación histórico se instaló tanto en el Estado como en la sociedad y se hizo "sentido común". Sentido de la autoridad, como ya hemos citado a Góngora, sentido del deber obligado ("pagar la obligación"), sentido de lo moral, de lo que se hace y se dice y de lo que se hace y no se dice. Se construyó un "nosotros" que muchos comparten, en que el ser de origen blanco hispánico, de ser católico o cristiano (ya sea de peregrinaciones a las vírgenes de Lo Vázquez o santos como Yumbel), de hablar en castellano (WCS: White, Christian, Spanish) ${ }^{39}$, son rasgos identitarios fuertes. Como sentenció George Mc Bride, "Chile se liberó de España pero no de las instituciones españolas; labró su Independencia pero no hizo una Revolución"

\section{LA GRAMÁTICA DEL RACISMO Y DEL CONSERVADURISMO}

El racismo de cada día se fundamenta en este inconsciente identitario. Quienes no comparten estas características (WCS) están en las fronteras de la chilenidad.

39. Me refiero en un cierto juego de palabras al WASP (White, Anglo-Saxon and Protestant). Ver: Samuel Huntington. Who Are We? The Challenges to America's National Identity. Samuel and Schuster (2004).

40. George Mc Bride fue un geógrafo norteamericano contratado por Carlos Dávila, en ese entonces embajador de Chile en Estados Unidos y posteriormente líder de la República Socialista. Escribió un maravilloso libro titulado Chile, su tierra y su gente. Icira. 1971. 
En una investigación realizada hace unos años en la Cordillera de Nahuelbuta, en el sur de Chile, tratamos de comprender lo que denominamos "la "gramática del racismo", esto es, un conjunto de reglas de convivencia de dos grupos humanos, semejantes en la disponibilidad de bienes y acceso al poder, separados por, casi exclusivamente, un asunto de origen étnico o racial ${ }^{41}$. El estudio analizaba comunidades mapuche(s) vecinas de comunidades de colonos pobres chilenos. La investigación se enfrentó a uno de los aspectos más difíciles de tratar en los temas de la cultura como es a) la visión que las personas y grupos humanos tienen de los otros; b) las fronteras que se establecen entre comunidades, habiéndose descubierto situaciones con "fronteras blandas" y situaciones con "fronteras duras"; c) la conciencia de identidad no indígena o indígena y cómo se construye una y otra; d) la autoconciencia de superioridad e inferioridad (el término "mapuchitos" empleado por unos y otros en diversas circunstancias); y d) el análisis de los fundamentos del racismo en comunidades que conviven casi cotidianamente.

Este es un tema, como en todas partes del mundo, silenciado, ocultado ("secretos públicos") hasta que se hace explosivo, conflictivo y evidente. En los casos estudiados se encuentra una gama muy amplia de situaciones que va desde la evidencia de separación y donde opera en forma plena el "principio de la distinción por oposición", hasta otros lugares donde se impone el "principio de la integración" (todos somos iguales, aquí no se hacen distinciones), a pesar de las prácticas claramente discriminatorias y divisorias. El discurso de integración a veces aparece coherente con la práctica de integración y a veces contradictorio con una práctica de discriminaciones y separaciones. En las entrevistas aparecían situaciones altamente complicadas en la apreciación de los campesinos chilenos de sus vecinos mapuche(s); asuntos como olores corporales, facciones, color y forma del cabello, hasta estereotipos sexuales, forman esta gramática silenciada y existente. Un aspecto estudiado fue la opinión de técnicos agrícolas sobre las posibilidades de desarrollo y éxito de comunidades aledañas separadas por su pertenencia étnica. En un caso los técnicos se aventuraban a señalar que el traspaso de tecnología e inversiones sería exitoso y en el otro, mapuche, la profecía era autocumplida, se pensaba que no darían resultado las innovaciones y por cierto, no daban resultado.

Las autopercepciones acerca de la identidad nacional forjada en el valle central son elementos profundos, quizás los más complejos, de la nacionalidad. Las fronteras étnicas en Chile, sin embargo, además de ser inconscientes coinciden con las fronteras territoriales peligrosas, el norte cholo y el sur mapuche. El avance de las tropas y población del valle central, del Estado y de la sociedad allí adscrita hacia

41. Proyecto Fondecyt No1971125. "Vivir en la subsistencia”. Concurso Regular. 1997. 
el norte y hacia el sur a fines del siglo XIX y comienzos del XX, surge de esta idea subterránea de superioridad. En ambos casos una campaña de "chilenización" logró establecer una conciencia nacional fuera del valle central y de una virulencia extraordinaria que ha conducido a que sean poblaciones reacias a cualquier solución moderna, tanto en los asuntos del norte como en los de la frontera del sur. ${ }^{42}$

La centralidad de la Guerra de Arauco en la cohesión de la derecha chilena a lo largo de la historia es una evidencia de la mayor importancia y una fuente no menor de explicaciones de lo que es el inconsciente colectivo y las raíces de la nacionalidad, plenamente vigentes. Chile central, el Estado, la sociedad formada en su entorno y que a la vez lo maneja y aprovecha (como es hoy público y notorio) poseen una convicción de superioridad a la que adscribe un sector amplio de los estratos populares. Serían, en el lenguaje que estamos empleando, los siervos no rebelados.

La preocupación general de los cientistas políticos y sociólogos acerca del voto popular de derecha tiene en estos elementos, pensamos, su explicación profunda. El sentimiento autoritario juega en ambas direcciones, en quienes lo ejercen desde el poder y quienes lo aceptan como parte integrante del sistema. No es casualidad que la relación de clientelismo sea la que domina en la política chilena, tanto en el ámbito de la derecha como también en partidos de centro e incluso de centro izquierda. Las alcaldías son en su generalidad sistemas de manejo de clientelas cautivas, juego permanente de intercambios de bienes y simbólicos. El alcalde, cual nueva forma de hacendado, dona canastas familiares, zinc para los techos, alambre para cierros, fardos de pasto para el ganado y en la Navidad, regalos a los niños. No en pocos casos en el día de aniversario de la municipalidad se hacen fiestas en que el alcalde y las autoridades locales beben y se emborrachan en conjunto con la población, al igual que lo hacían los "buenos patrones" en días de trillas y rodeos en las viejas haciendas del valle central.

"Asi surgieron el dominio autoritario, el obscurantismo, los prejuicios, el espíritu de tribu y de partido, y toda la larga y estrecha faja de incomprensión que tanto retardó la evolución social y espiritual de Chile. Sobre todo, que hace muy difícil en la actualidad una vuelta al gobierno del pueblo, ya que este y sus líderes se formaron en un ambiente de tan baja calidad moral, que los hace ineficaces y hasta peligrosos frente a las responsabilidades que deberían asumir. No, decididamente el campo chileno no cuenta con mi simpatía...."

42. Ver Sergio González Miranda. ElDios cautivo. Las Ligas Patrióticas en la chilenización compulsiva de Tarapacá (1910-1922). Editorial LOM. 2004.

43. Esto escribe Benjamín Subercaseaux en el año 1940 en un curioso libro que es bien conocido 
Poco habría que agregar a esta cita escrita con pasión hace 80 años. No cabe mayor duda de que la denominada "modernidad" se ha alejado de nuestras costas a medida que han ingresado las "modernizaciones". Sucedió igualmente en el siglo XIX, en que los hacendados traían las máquinas más modernas desarrolladas en la Inglaterra de la Revolución Industrial y trataban de "niños" a los inquilinos (muchos de ellos ya viejos) y jugueteaban o simplemente se aprovechaban de las "chinas" (sus hijas), o simplemente las violaban. Modernización tecnológica y modernidad de la cultura son dos movimientos que en Chile han transitado separados y muchas veces opuestos. Hoy por hoy, el acceso masivo a Internet, el uso compulsivo de celulares inteligentes, en fin, el acceso a esas tecnologías, no tiene en absoluto implicancias en el desarrollo de la modernidad ${ }^{44}$.

\section{LA FORMACIÓN DEL PUEBLO NACIÓN MAPUCHE COMO CONSECUENCIA DE LA FORMACIÓN DE UN ESTADO DE CONQUISTA EN EL CHILE CENTRAL}

La contra tesis es clara. Así como en toda relación dialéctica, ambos opuestos se construyen, destruyen y reconstruyen mutuamente. Como es evidente y de una simpleza casi absurda, hay indígenas porque hay no indígenas. En la medida en que unos se construyen en oposición a los otros, en la otredad, al decir de modo sofisticado, los otros también se construyen, formalizan fronteras, amplían espacios de disidencia y espacios comunes.

En Chile ha habido dos tesis opuestas que se han disputado el campo de análisis histórico sin demasiado éxito. Por una parte, la tesis de que habría existido una guerra interminable y permanente en el sur araucano y, por tanto, en la que los

casi exclusivamente por su título: Chile o una loca geografía (Editorial Universitaria. Edición del 2011). El prólogo fue nada menos que de Gabriela Mistral. Son opiniones y reflexiones libres de una suerte de viajero por los distintos lugares del país. A veces sus opiniones son extremadamente certeras, como la que ponemos en el texto. Podríamos decir hoy (2018) lo mismo: "Nuestra agricultura actual crea piltrafas de humanidad hambrienta, sin voluntad ni iniciativa" (página 170).

44. La derecha chilena, portadora de estas ideas pre modernas, propias de siglos anteriores, sobre la familia, el uso del cuerpo, la propiedad privada, en fin, las bases de la sociabilidad, ha mantenido una adhesión siempre cercana al 50\% de la ciudadanía que ejerce sus derechos electorales. Más aún, lo que ha mostrado la elección presidencial del año 2017 es que tiene una capacidad de movilización enorme en base a esas ideas y conceptos propios de una era hacendal, que aunque inexistente quizá en términos materiales se proyecta simbólicamente más allá de sus tiempos de gloria. Los esfuerzos liberales en el ámbito de la derecha son ínfimos y siempre han sido golondrinas que no hacen verano. 
contactos se minimizan. La contraria ha sido denominada como la de "los estudios fronterizos", la que reaccionando sobre un historial bélico fantasmagórico enfatiza la existencia de relaciones pacíficas, de colaboración, de intercambio ${ }^{45}$.

El primero de los planteamientos ha servido para apoyar un discurso patriotero en que el araucano aparecería como una suerte de antecedente épico en la conformación de la nación. Ese discurso tuvo éxito en los inicios de la República y hay numerosos testimonios en que los así denominados "patriotas" se referían con emoción a la "gesta araucana". De ahí el rojo de las banderas, "la sangre araucana", el espíritu de libertad y finalmente el "jamás vencidos” del Ejército de Augusto Pinochet Ugarte. La crítica historiográfica no se hizo esperar y por cierto que es un facilismo cronológico: ha habido largos periodos en que el enfrentamiento bélico no ha existido. Eso no justifica que en esos periodos haya habido inclusión, conciliación, integración y ruptura de fronteras ${ }^{46}$.

La tesis contraria trató no solamente de establecer lo errado del carácter bélico permanente, sino sacar conclusiones sobre la integración o inclusión de los mapuche(s) a la sociedad fronteriza, mestiza y chilena, finalmente ${ }^{47}$. La discusión sin duda no tiene término, ya que se confunde el mestizaje físico con la identidad de los mapuche(s). De lo primero no cabe mucha duda y está bien demostrado en la historiografía nacional, pero ello no significa que se haya perdido la propia conciencia de ser una agrupación diferente a la de los chilenos; esto, alimentado por la relación ya desarrollada en este trabajo.

Los hechos, sobre todo los acontecimientos complejos del tiempo presente, desdibujan ambas interpretaciones y muestran que la realidad de los hechos es una combinación de múltiples factores. No cabe, sin embargo, mucha duda de que siguiendo los principios de la hermenéutica, así como nos ven, nos comportamos, y como nos comportamos nos miramos a nosotros mismos, en una versión libre de los trabajos de Paul Ricoeur. La mirada patriótica y militarista influye en los propios

45. Esta tesis está desarrollada por el historiador Sergio Villalobos en su libro Relaciones fronterizas en la Araucanía. Ediciones Universidad Católica de Chile. Santiago, 1982. Después de ese libro hay numerosos trabajos que han seguido ese derrotero. Sergio Villalobos, "Vida fronteriza en la Araucanía: el mito de la Guerra de Arauco". Andrés Bello, 1995.

46. José Pérez García. La Paz de Negrete. En Historia de Chile con prólogo de José Toribio Medina. Publicado originalmente en la Colección de historiadores de Chile y de documentos relativos a la historia nacional. Imprenta del Ferrocarril. 1861. Reproducción digital en: www. memoriachilena.cl.

47. “...hay que tener en cuenta que los araucanos, mal llamados 'mapuches', son mestizos con una fuerte carga blanca, igual que todos los chilenos de norte a sur”. Sergio Villalobos en Reportajes de ElMercurio. 15 de enero del 2017. Y agrega acerca del carácter de guerreros de los mapuches, calificándolo como "uno de los mitos más tenaces y falsos de nuestra historia". 
mapuche(s), de tal suerte que se auto erige, por ejemplo, la figura del guerrero o weichafe, como una contraposición a la mirada que hemos denominado como patriótica ${ }^{48}$. Un juego de espejos pareciera inevitable.

Por cierto que la mirada negociadora, pacifista e integracionista también tiene fuerza y argumentos, siendo una gran cantidad los mapuche(s) que se encuentran en situaciones auto consideradas de participación plena en la ciudadanía chilena.

Pero el elemento contructivista nuevo en la larga tradición mapuche es su paso de una compleja red de agrupaciones, dispersas y no pocas veces opuestas, propias de una sociedad segmentaria, a una noción cada vez más centralizada de pueblo y nación. Todos quienes hayan leído a Anderson y la moderna literatura sobre el significado de la nación saben que ella ha sido y es una invención fruto de una voluntad de performance histórica. Es una comunidad imaginada, nos dice Anderson ${ }^{49}$. Un acto de voluntad, como señaló en su momento Renán para Francia. Por cierto que implica una alta cuota de poder, esto es, de condiciones que permitan que diferentes agrupaciones pasen a comprenderse como un solo pueblo y ese conglomerado pase a expresarse como un solo cuerpo nacional, una "nación". De allí a la formación del Estado o de diferentes sistemas institucionales de representación del carácter nacional, hay un paso.

Digamos nuevamente la idea central de este artículo. Las naciones se construyen siempre en base a fronteras, imaginadas por cierto, pero que con el tiempo se hacen reales, duras, a veces de piedra y suelen conducir a los mayores desastres humanos, a las guerras, a las discriminaciones, a las xenofobias, a consideraciones de superioridad inaceptables. En Chile, la nacionalidad se formó y se sigue construyendo en base a esas fronteras a veces territoriales y muchas veces simbólicas. A veces son intentos

48. 'De esa forma es que el Weichafe adquiría el 'Newen' (Poder), el 'Newen Mapu' (poder de la tierra), el 'Newen Lüfke' (poder del relámpago), venido de los animales totémicos respectivos de cada guerrero, muchas veces, emparentados al clan o familias respectivas, quienes provenían de un mismo 'Rewe' o ancestro. Es el momento en el cual se inicia el 'Inchin Aukan' (yo resisto), concepción que hace referencia a que la tierra que pisas es sagrada, y es por eso que el arte de la guerra no proviene del odio si no del 'Dwan' (amor a la tierra madre o patria)". Este tipo de afirmaciones es muy común y tiene una apariencia de rigurosidad histórica: "La rigurosa preparación física/mental e espiritual y la destreza en el manejo de las armas, hizo del araucano un guerrero digno de ser considerado uno de los mejores en el mundo, por su capacidad física, su alta motivación patriótica, su severa disciplina, por un verdadero culto al cuidado y manejo de las armas, por su capacidad de soportar el frío, el calor, el hambre, la sed y el dolor y desprecio por la muerte." www.elciudadano.com, 8 de junio de 2015. Sin autor.

49. Benedict Anderson. Comunidades imaginadas. Reflexiones sobre el origen y la difusión del nacionalismo. Fondo de Cultura Económica, México, 1993. 
ridículos e ineficaces como la "Operación Huracán”, montada por el Gobierno y la policía el año 2017 y 2018, esto es, al momento de escribir este trabajo ${ }^{50}$.

Las élites son, en todos los casos, los ejes clave de estos procesos de construcción de nuevas nacionalidades. Y en el caso mapuche estas son cada vez más amplias, con exposición más larga al sistema educativo oficial, con capacidad de lazos y alianzas multinacionales, con conocimientos de procesos semejantes en otras latitudes, con viajes e intercambios fruto de la globalización, mundialización o como se quiera denominar el proceso masivo de ruptura de fronteras que existe en la actualidad ${ }^{51}$.

Si bien hay un conjunto de antecedentes históricos, el fenómeno del "nacionalismo mapuche" es nuevo y difícil de comprender por las autoridades nacionales chilenas. El refuerzo de las actitudes de conquista, de sometimiento colonial, de afirmación un tanto histérica de la necesidad de "un solo pueblo, una sola nación y un solo Estado" en el territorio nacional, ha conducido y conducirá probablemente a una espiral cada vez más pronunciada. La historia no es en todo caso lineal y por tanto nada dice que esa sea la evolución de esta contradicción y que no se pueda resolver en caminos alternativos. Pero de eso nadie puede estar seguro.

50. Ver cita anterior de la Revista The Clinic. José Bengoa "Jamás vencidos", The Clinic (Jueves 5 de octubre de 2017)

51. Pocos años atrás habría sido impensable el viaje de la machi Francisca Linconao a Bolivia en enero del 2018 y la cobertura mediática en torno a ella. "Los latifundistas están enojados conmigo porque fui la primera machi en usar el convenio 169 de la OIT". www.eldesconcierto.cl/tag/machifrancisca-linconao/ 